\title{
Assumptions of age and mobile handset type
}

\author{
Erin I. Walsh BSc a \\ Jay K. Brinker PhD b
}

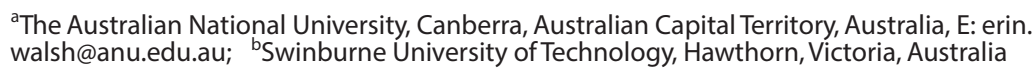

E.I. Walsh, J.K. Brinker, Assumptions of age and mobile handset type. Gerontechnology 2014;12(3):169-173; doi:10.4017/gt.2014.12.3.005.00 As mobile handsets become more sophisti cated, they are capable of supporting increasingly sophisticated applications and software which can be used for mobile telephone based interventions, treatment, research and telecare. Though it is generally accepted that older individuals will own less sophisti cated handsets, this brief study assesses age-associated factors relating to the type of mobile handset (cell phone, web phone, or smart phone) in more detail. Three hundred and twenty six Australian participants aged between 5 and 79 reported their age at first mobile purchase, and who initiated and made the purchase. Mobile handset type was significantly associated with both age and current everyday usage. It was concluded that current age, rather than age at time of purchase, was a simple and sufficient indicator of current phone handset type.

Keywords: aging, mobile telephone, short message service

Mobile telephones are increasingly being used in health and psychology settings, such as re minders to increase attendance for medical and psychological appointments ${ }^{1,2}$ as part of interventions and treatment (i.e. ${ }^{3,4}$ ), and as a tool used in psychological research (i.e. ${ }^{5,6}$ ). The sophistication of a mobile telephone's handset, including its computational power and software capabilities, defines the scope with which it can be used for interventions, treatment, research, and telecare. Basic cell phones are limited to voice calls and text messaging, while more mod ern smart phones support apps, internet brows ing, and other multimedia capabilities that may enhance interventions or research. The specific applications of mobile technology in health and psychology settings change with the age of the client or patient. For example, heath care appli cations generally focus on education for young adult users ${ }^{5,7}$ and telecare for elderly users ${ }^{8,9}$.

The type of mobile handset individuals are likely to own also changes with age ${ }^{10}$. As mobile hand set type dictates how mobile telephone technol ogy may be used, understanding the relationship between mobile handset type and age could in form better targeting of mobile telephone-based interventions and research across different age groups. In general, older individuals tend to use their mobiles less, have older mobile handsets ${ }^{10}$, and have access to less sophisticated mobile ca pabilities ${ }^{11}$ than younger individuals. Chronologi cal age is easily obtained as a matter of course in health and research settings, and is broadly helpful in guiding researchers and health prac titioners' expectations of likely mobile handset type. However, it may be more informative to consider the age of first mobile purchase, and who had control over that purchase.

The point in life when individuals first had access to mobile technology contributes to their current usage $^{10}$, and whether they are likely to upgrade their mobile handset ${ }^{12}$. Younger individuals were exposed to relatively sophisticated mobile tele phones early in life ${ }^{13}$. Older Australian individuals were initially exposed to more primitive mobile technology following the establishment of the first cellular network in $1987{ }^{14}$. Though they have been party to the ensuing advancement of mo bile technology, older individuals are less likely to upgrade their mobile handset than younger individuals ${ }^{12}$, indicating that the older a person was when they obtained their first mobile phone, the more basic their current phone is likely to be.

Another consideration is who initiated and made the mobile purchase. Research with 10-11 year old children found that $80 \%$ said it was their idea to have their first mobile phone ${ }^{15}$, though it is most often bought for them by their parents ${ }^{16-18}$. In this scenario, the type of mobile purchased may be at the parents' discretion, rather than the child's. For older adults, it is often their adult children who make the choice that their parents should have a mobile phone ${ }^{21}$. Here, the type of mobile purchased may be at the adult child's discretion, rather than the older parents'. In both cases, the initiator and purchaser of the mobile may dictate the type of mobile handset purchased. If this oc curs, the relationship between age at purchase and the type of mobile handset may be affected. 
This brief study examines whether age at first purchase, and the age-related factors surrounding that purchase, are more informative than current chronological age in predicting current mobile handset type. It then explores whether current handset type is associated with how much the mobile is used for basic communication (specifically, voice calls and SMS or text messages) as well as, whether it can be uniformly expected that younger participants will have smart phones and older participants will have cell phones. The first hypothesis is that the age at which participants obtained their first mobile phone will be correlated with their current mobile handset type. The second hypothesis is that the relationship between age of first mobile purchase and mobile handset type will be mediated either by who made the choice that a mobile should be purchased, or who purchased the mobile, or both.

\section{Method}

The ethical aspects of this research were approved by the Australian National University Human Research Ethics Committee.

\section{Participants}

The current study forms part of a larger investigation regarding the way in which age affects engagement with mobile telephones. Data for three, focussed studies was collected simultaneously from the same group of participants; the other two topics focussed on different aspects of how people perceive SMS, and its application as a tool for researchers.

Three hundred and twenty four (324) members of the general Australian public aged between 5 and 79 took part. Sixty two percent were female, and the majority $(80 \%)$ owned at least one mobile phone. Participants were recruited via an online panel service, with representativeness across age groups ensured by specifying demographic quota (a minimum of fifty participants from each of the following age bands: 5-14, 15-29, 29-35, $36-49$, and 50 or older). The panel service offered sampling from the general Australian population, though precise representativeness of the population as a whole is not known. Participants were offered small monetary compensation for their participation.

\section{Materials and procedure}

Participants completed an online self-report questionnaire $^{19}$ regarding the purchase of their first mobile phone, and current mobile phone usage.

The major outcome variable is categorical in nature (as one can own a cell, web, OR smart phone), whilst predictor variables may be continuous (i.e. age) or categorical (i.e. whether the self OR others purchased the mobile). Logistic regression allows analysis of both continuous and categorical variables, and produces odds ratios which are useful in guiding interpretation. The relationship between the independent variable and dependent variable is shown by $b$, the slope of the relationship. A positive $b$ indicates a positive relationship, $a$ negative $b$ a negative relationship, and the value of $b$ indicates the magnitude of the relationship. The statistical significance of the relationship is indicated by a $t$ statistic; its associated $p$ value must be equal to or below 0.05 for the relationship to be considered significant. Overall model fit is denoted by pseudo $R^{2}$, which works on the same principal as $R^{2}$ values used in ANOVA and other regression analyses, but account for the categorical nature of data within the logistic regression model. McFadden's Pseudo $R^{2}$ was used here due to its conceptual similarity to $\mathrm{R}^{2}$-statistics used in ANOVA and other regression. Finally, likelihood ratio tests are used to compare logistic regression models, indicating whether one particular model fits the data significantly better than another. As with the slopes in the logistic regression model, significance is indicated by a $p$ value equal to or below 0.05 .

\section{ResULTS AND DISCUSSION}

The first hypothesis, that the age at which participants obtained their first mobile phone will be significantly associated with the type of their current mobile handset, was supported. The age at which a mobile phone was first purchased was significantly positively correlated with chronological age $(r=0.91, p<0.01)$ showing the older a person is now, the older they were when they got their first mobile phone. Descriptively, participants currently using a cell phone obtained their first mobile phone at an average 32 years of age, those currently using a web phone at 28 years of age, and those currently using a smart phone at 20 years of age. The relationships between variables of interest, chronological age, and age at purchase, are pictured in Figure 1.

Logistic regression revealed that overall, participants were significantly more likely to own a smart phone than a cell phone $(b=3.105, t=8.20$, $\mathrm{p}<0.001$, McFadden's Pseudo $\mathrm{R}^{2}=0.083$ ). They were not significantly more or less likely to own a web phone than a cell phone $(b=-0.260$, $t=-0.473, p=0.635)$. Age when the first mobile telephone was purchased was significantly associated with the type of mobile phone participants had, with an older age at first purchase significantly associated with a lower likelihood of currently owning a smart phone $(b=-0.066, t=$ $5.43, p<0.001)$, but not a web phone $(b=-0.0168$, $\mathrm{t}=-1.01, \mathrm{p}=0.308$ ) rather than cell phone. The transition in age from primarily purchasing smart 


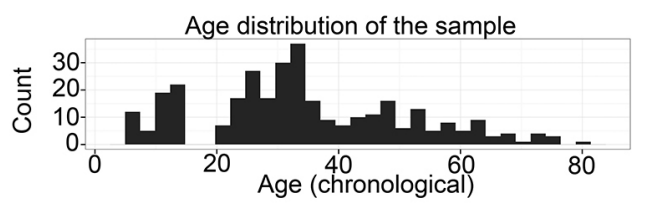

Type of mobile telephone owned
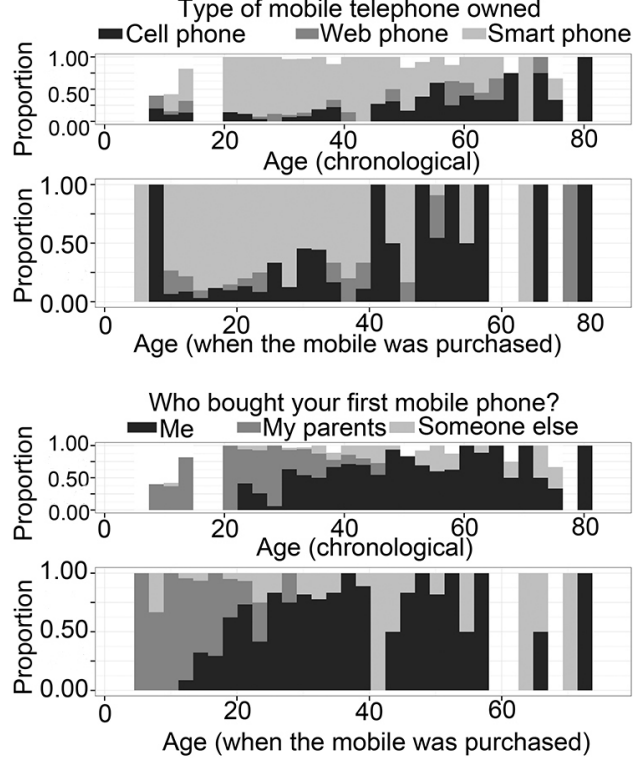

Was it your idea to have a mobile phone, or did someone else make the decision for you?
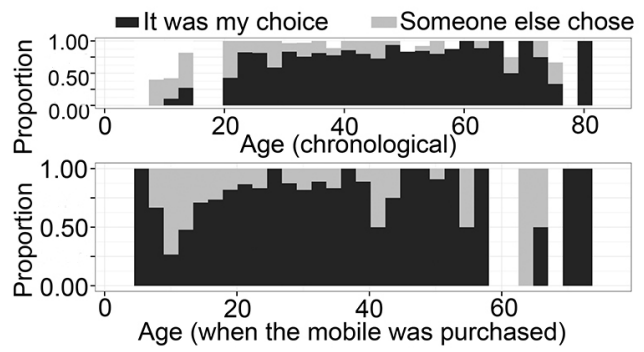

Figure 1. Age, mobile type, and factors impacting on first mobile purchase; white space indicates missing data, either due to non-response, or participants in that age band not owning a mobile telephone

phones to primarily purchasing cell phones was relatively sharp. With each increasing year of age at first purchase, the odds of buying a smart phone at first purchase decreased 0.93 fold with each year.

To establish whether age when a mobile phone was first obtained provided meaningful data beyond chronological age in predicting type of mobile handset, logistic model comparison by way of likelihood ratio tests was completed. The first model consisted or chronological age as a predictor of mobile handset type. The addition of age at first purchase as a predictor to this model significantly improved model fit, $X^{2}(2)=17.261$, $p<0.001$. Though multicollinearity confounds the usefulness of specific model coefficients in the model with both predictors, this suggests that an individual's age when purchasing their first mobile phone offers some information regarding mobile phone type, beyond just chronological age.

The second hypothesis was not supported. Even though both the initiator of first mobile purchase and who made the purchase were significantly associated with age at first purchase, they did not mediate the relationship between age of first mobile purchase and current mobile handset type. Overall, $76 \%$ of respondents felt they, rather than someone else, initiated the purchase of their first mobile phone. Twenty per cent of those who initiated the purchase themselves currently own a cell phone (rather than a smart or web phone), in comparison to $13 \%$ of those who felt the decision was made by others.

Age at purchase significantly predicted whether it was the self or someone else who initiated the purchase (McFadden's Pseudo $R^{2}=0.033$; $b=-0.042, t=-2.929)$. However the initiator of the purchase did not mediate the relationship between age at purchase and current mobile handset type, as coefficients regarding the association between age at purchase and the likelihood of first obtaining a smart phone $(b=-0.066$, $t=-5.31, p<0.001)$ or a web phone $(b=-0.0166$, $t=-1.01, p=0.319)$ rather than cell phone, were unchanged by the addition of purchase initiator into the model (McFadden's Pseudo $\mathrm{R}^{2}=0.08$ ).

Overall, 51\% of participants bought their first mobile phone themselves, while 39\% had it bought for them by their parents. Only $10 \%$ had it bought for them by someone else, an aggregate category collapsed across purchases made by children, friends, work or partners due
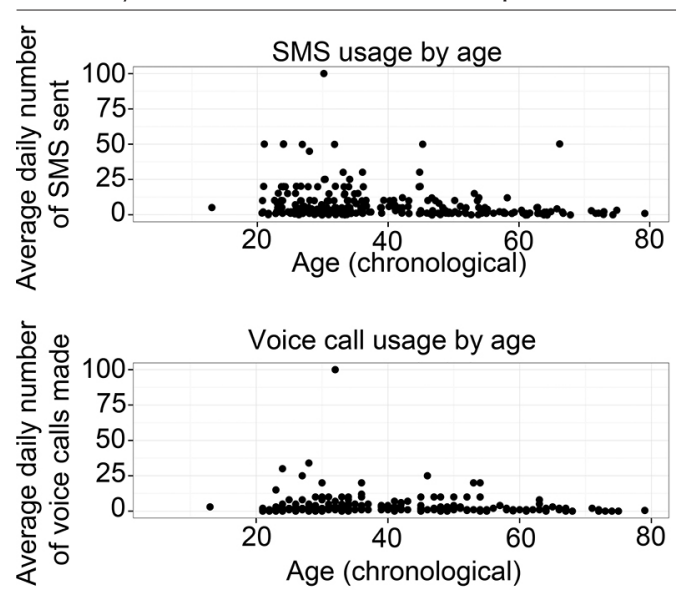

Figure 2. Average SMS (Short Message Service) and voice call usage by age 
to low numbers in each category. Thirty two percent of those who bought their first mobile for themselves currently own a cell phone (rather than a smart or web phone), in comparison to $9 \%$ of those whose parents made the first purchase, and $38 \%$ of those who had the purchase made for them by someone else.

Age at purchase significantly predicted who bought the first mobile phone, with the odds that parents would make the purchase decreasing $(b=-0.27, t=-6.66, p<0.001)$, and the odds that someone else would make the purchase increasing $(b=0.03, t=2.27, p=0.022)$. Odds ratios indicate that with each passing year, the likelihood of parents buying the first mobile decreased 0.76 fold, and the likelihood that someone else would make the purchase increased 0.03 fold. The mean age at purchase where parents bought the mobile was lower (15 years) than where the participant bought their own mobile (27 years), which in turn was lower than where someone else bought the mobile (34 years). This is in line with the literature that children's first mobile is often bought by their parents $\mathrm{s}^{16,17,20}$, and suggests that to a lesser degree older adults are more likely than younger adults to have their first mobile bought for them by someone else. However the purchaser did not mediate the relationship between age at purchase and current mobile handset type, as coefficients reading the association between age at purchase and the likelihood of first obtaining a smart phone $(b=-0.065, t=-4.38, p<0.001)$ or a web phone $(b=0.006, t=0.300, p=0.764)$ rather than cell phone, were unchanged by the addition of who made the purchase into the model (McFadden's Pseudo $\mathrm{R}^{2}=0.094$ ).

Of those in the sample who owned a mobile telephone, most (73\%) owned a smart phone, with $19 \%$ owning a cell phone and $8 \%$ owning a web phone. The commonality of smart phones is heartening for psychological and health interventions seeking to use mobile handsets for more sophisticated applications, such as apps or multimedia content. The relationship between phone type on basic communication (average self-reported daily usage of SMS and voice calls) was assessed with non-parametric Kruskal-Wallis tests, used in place of a one way ANOVA due to D'Agostino tests revealing significant positive skew in both number of voice calls, and number of SMS sent on an average day (skew $=8.604, \mathrm{z}=11.41, \mathrm{p}<0.001$; and skew $=3.823$, $\mathrm{z}=8.37, \mathrm{p}<0.001$ respectively). The skew was due to most participants only moderately using SMS and voice calls, but a sizeable portion of heavier users. The type of mobile handset was significantly related to the number of SMS sent per day $\left(\mathrm{X}^{2}(2)=43.401, \mathrm{p}<0.001\right)$ and number of voice calls made per day $\left(X^{2}(2)=24.364\right.$, $p<0.001)$. Participants using a cell phone sent an average of two SMS and made an average of one voice call per day, in contrast to seven SMS and four voice calls by those using a web phone, and nine SMS and four voice calls by those using a smart phone. As handset type is associated with basic mobile usage behaviour, psychology and healthcare professionals may expect more participant engagement with mobile telephone based communication in smart phone users, than cell phone users.

Linear regression was used to examine whether age was associated with basic mobile usage, beyond the impact of mobile phone handset type. Once a single individual outlier (claiming to send 100 SMS and engage in 100 voice calls daily) was removed, current participant age was significantly negatively associated with average self-reported daily SMS usage $(b=-0.15, t=3.560, p<0.001)$, but not when mobile type was added into the model $(b=0.01, t=0.48, p=0.65)$. This suggests that, whilst younger individuals do use SMS more on a daily basis than older individuals, the relationship between mobile type and SMS usage overlaps considerably with the relationship between age and SMS usage. There was no significant association between age and average number of voice calls per day ( $b=-0.0333, t=1.53, p=0.127)$.

\section{Conclusion}

In summary, psychological and health researchers can look to more sophisticated applications with the expectation that large portions of the population will have access to smart phones, though there was support for the general assertion that older individuals are likely to own less sophisticated mobile handsets ${ }^{10,11}$. Particularly relevant to applications with the elderly, such as telecare, an increase in age was significantly associated with an increased likelihood of owning a cell phone, rather than a smart phone. This suggests that appointment reminders, interventions, treatment, and research targeted toward an older population should not assume smart phone ownership, and thus consider using communication techniques that do not rely on app installation or multimedia, but rather on basic functionality such as voice calls or SMS.

Whilst age first mobile purchase was significantly associated with whether the participant or someone else initiated the purchase of a mobile phone, and who made the purchase, this additional information did not significantly impact on the relationship between age and purchase and current mobile handset type. Though age at first purchase was a slightly 
better predictor of mobile handset more than chronological age, the strong positive correlation with chronological age indicates that either measure could viably be used. In a practical sense, chronological age is more available to researchers, as obtaining age at first mobile

\section{References}

1. Ashby R, Turner G, Cross B, Mitchell N, Torgerson D. A randomized trial of electronic reminders showed a reduction in the time to respond to postal questionnaires. Journal of clinical epidemiology 2011;64(2):208-212; doi:10.1016/j. jclinepi.2010.01.020

2. Kharbanda EO, Stockwell MS, Fox HW, Rickert VI. Text 4 health: a qualitative evaluation of parental readiness for text message immunization reminders. American Journal of Public Health 2009;99(23):2176-2178; doi:10.2105/ AJPH.2009.161364

3. Fjeldsoe BS, Marshall AL, Miller, YD. Behavior change interventions delivered by mobile telephone short-message service. American journal of preventive medicine 2009;36(2):165-173; doi:10.1016/j.amepre.2008.09.040

4. Revelle G, Reardon E, Green MM, Betancourt J, Kotler J. The Use of Mobile Phones to Support Children's Literacy Learning. LNCS 2007;4744:253-258; doi: http://dx.doi. org/10.1007/978-3-540-77006-0_31

5. Ebner-Priemer UW, Kubiak T, Pawlik K. Ambulatory Assessment. European Psychologist 2009;14(2):95-97; doi:10.1027/1016-9040.14.2.95

6. Gold J, Lim MSC, Hocking JS, Keogh L, Spelman T, Hellard ME. Determining the impact of text messaging for sexual health promotion to young people. Sexually transmitted diseases 2011;38(4):247-252; doi:10.1097/ OLQ.0b013e3181f68d7b

7. Yu LA, Sacher H, Louden G. Buddysync: pensando en los móviles para crear una aplicación inalámbrica de tercera generación para los jóvenes norteamericanos [Buddysync: Thinking beyond cell phones to create a third-generation wireless application for U.S. Teenagers]. Revista de Estudios de Juventud 2002;57:173-188

8. Botsis T, Demiris G, Pedersen S, Hartvigsen G. Home telecare technologies for the elderly. Journal of telemedicine and telecare 2008;14(7):333337; doi:10.1258/jtt.2008.007002

9. Lee $\mathrm{HJ}$, Lee $\mathrm{SH}, \mathrm{Ha} \mathrm{KS}$, Jang HC, Chung WY, Kim JY, Chang, Y.S, Yoo DH. Ubiquitous healthcare service using Zigbee and mobile phone for elderly patients. International journal of medical informatics 2009;78(3):193-198; doi:10.1016/j. ijmedinf.2008.07.005

10. Ling R. Should We Be Concerned That the Elderly Don't Text? The infor- purchase requires additional questioning beyond basic demographic information. In conclusion, results indicate that future researchers seeking to use mobile telephones can make assumptions regarding the likely type of handset participants will own, on the basis of their chronological age.

mation society 2008;24(5):334-341;

doi:10.1080/01972240802356125

11. Mackay MM, Weidlich O. Austrailan Mobile Phone lifestyle index. 9th edition. Sydney: Australian Interactive Media Industry Association Mobile Industry Group; 2009

12. Huh YE, Kim SH. Do early adopters upgrade early? Role of post-adoption behavior in the purchase of next-generation products. Journal of Business Research 2008;61(1):40-46; doi:10.1016/j. jbusres.2006.05.007

13. Inyang I, Benke G, Dimitriadis C, Simpson P, McKenzie R, Abramson M. Predictors of mobile telephone use and exposure analysis in Australian adolescents. Journal of paediatrics and child health 2010;46(5):226-233; doi:10.1111/j.14401754.2009.01675.x

14. Goggin G. Introduction - Mobile Phone Cultures. Continuum 2007;21(2):133-135

15. Davie R, Panting C, Charlton T. Mobile phone ownership and usage among pre-adolescents. Telematics and Informatics 2004;21(4):359-373; doi:10.1016/j.tele.2004.04.001

16. Charlton T, Panting C, Hannan A. Mobile telephone ownership and usage among 10- and 11-year-olds. Emotional and behavioural difficulties 2002;7(3),37-41; doi:10.1080/10304310701278181

17. Ling R, Haddon L. Children, youth and the mobile phone. In: Drotner K, Livingstone S, editors, The international handbook of children, media and culture. London: Sage; 2008; pp 137-145

18. Lorente $S$. Juventud y teléfonos móviles: algo más que una moda [Youth and mobile telephones: more than a fashion]. Revista de Estudios de Juventud 2002;57:9-24

19. http://tinyurl.com/handset-age-study; retrieved November 20, 2014

20. Oksman V, Rautiainen P. Toda mi vida en la palma de mi mano: la comunicación móvil en la vida diaria de niños y adolescentes de Finlandia ['I've got my whole life in my hand' mobile communication in the everyday life of children and teenagers in Finland]. Revista de Estudios de Juventud 2002;57;25-32

21. Mallenius S, Rossi M, Tuunainen V. Factors affecting the adoption and use of mobile devices and services by elderly people-results from a pilot study. Los Angeles: 6th Annual Global Mobility Round Table; 2007 